\title{
Linkage of social care and hospital admissions data to explore non-delivery of planned home care for older people in Scotland
}

Word count (abstract): 263

Word count: 2,494

Accepted for publication in Quality in Ageing and Older Adults published by Emerald. 


\begin{abstract}
Purpose: As part of a pilot study assessing the feasibility of record-linking health and social care data, we examined patterns of non-delivery of home care among older clients ( $>65$ years) of a social home care provider in Glasgow, Scotland. We also assessed whether non-delivery was associated with subsequent emergency hospital admission. Design: After obtaining appropriate permissions, the electronic records of all home care clients were linked to a hospital inpatient database and anonymised. Data on home care plans were collated for 4,815 older nonhospitalised clients, and non-delivered visits examined. Using case-control methodology, those who had an emergency hospital admission in the next calendar month were identified $(n=586)$, along with age and sex-matched controls, to determine whether non-delivery was a risk factor for hospital admission. Findings: There were 4,170 instances of 'No Access' non-delivery among 1,411 people, and 960 instances of 'Service Refusal' non-delivery among 427 people. The median number of undelivered visits was two among the one third of clients who did not receive all their planned care. There were independent associations between being male and living alone, and non-delivery, while increasing age was associated with a decreased likelihood of non-delivery. Having any undelivered home care was associated with an increased risk of emergency hospital admission, but this could be due to uncontrolled confounding. Research Implications: This study demonstrates untapped potential for innovative research into the quality of social care and effects on health outcomes. Practical Implications: Non-delivery of planned home care, for whatever reason, is associated with emergency hospital admission; this could be a useful indicator of vulnerable clients needing increased surveillance.
\end{abstract}




\section{Introduction}

With an increasingly ageing population in the United Kingdom and nearly one-quarter (24\%) of the population expected to be aged over 65 years by 2040 (Office for National Statistics, 2015), policy in Scotland is directed towards keeping older people living in their own homes in order to maintain their quality of life and to reduce costs of institutional care (Scottish Government, 2011). Home (or domiciliary) care, usually involving a scheduled package of personal care and practical tasks assessed and delivered by local Council providers, is an essential source of support for older people, although there is a concern that with funding cuts, the gap between care needed and care received is increasing (House of Lords, 2013). The National Institute for Clinical Excellence (2015) published a guideline relating to the planning and delivery of care for older people living in their own homes which had a strong emphasis on person-centred care.

However, older people have voiced concerns over late and missed visits (Care Quality Commission, 2013), especially at weekends, that carers come at inconvenient times (Cattan and Giuntoli, 2010), and that there can be a lack of flexibility, especially on a day-to-day basis, to meet changing needs (Henderson, 2006). Given that missed visits can have implications for a client's health and well-being, guidance has been issued around these scenarios (National Institute for Clinical Excellence, 2015). However, there may be other situations whereby an older person may not receive the home care that is planned for them. For example, homecare workers may be unable to physically gain access to homes. Older people may 'refuse' home care visits at the point of delivery, or there may be a decision (by the client or homecare worker) that no service is required. These situations all constitute non-delivery of home care. When they arise among older people with complex problems and co-morbidities, such as dementia, there is a risk that vulnerable people are left unattended.

We conducted two studies. The aim of the first study was to examine patterns of non-delivery of home care, and how non-delivered visits are recorded, in a population of home care clients in Glasgow, Scotland. We questioned how commonly non-delivery occurs. The aim of the second study was to assess whether non-delivery of planned home care visits constituted a risk factor for subsequent emergency hospital admission among older clients. 
While it has been recognised that there is insufficient evidence on the role of home visits for the prevention of hospital admissions (Purdy and Huntley, 2013), NICE acknowledges that these 'can have implications for a client's health and well-being' (National Institute for Clinical Excellence, 2015). However, there is still limited information sharing between health and social care agencies in the UK, with the development of shared electronic records in its infancy (Maguire et al, 2018). Therefore to address the aims we needed to expressly link relevant health and social care datasets. Similar linkage projects across health and social care databases in other contexts have had varying linkage success, ranging from $78-95 \%$ in a study in England (Bardsley et al, 2012), 91\% in Wales (Porter and Morrison-Rees, 2015) and 99\% in Scotland (Witham et al, 2014). 


\section{Methods}

We worked with a large social care provider of home care services for the resident population of Glasgow City Council, Scotland $(n=600,000)$. This social care organisation provides $98 \%$ of home care to people in Glasgow, the majority to people aged 65 and over. Ethical approval for this work was obtained from the University of Stirling and Glasgow City Council. A threeway data sharing agreement was also set up between the social care provider, the University of Stirling and Glasgow City Council. All record-linkage and analysis was carried out within the Glasgow Safe Haven, a data warehouse set up by the Greater Glasgow and Clyde Health Board of the National Health Service. This is a secure environment that permits access to linked health datasets via dumb terminals. Governance of the Glasgow Safe Haven is via a Local Privacy Advisory Committee (LPAC), with embedded Standard Operational Procedures and Caldicott Guardian approval already in place.

The electronic records of all clients receiving home care services for the entire 3-month period from September to November 2013 were securely provided, thereby giving a snapshot of clients as they moved in and out of care provision. Using a master patient list of Community Health Index (CHI) numbers (a unique 10-digit number allocated to all patients registered with a General Practitioner in Scotland), CHI numbers were added to social care data using probabilistic techniques on the basis of name and address records. The home care database was then record-linked to a routinely-collected $\mathrm{CHI}$-indexed database of inpatient hospital admissions, known as Scottish Morbidity Record 1 (SMR1) (ISD Scotland, 2017). Data passed to researchers for subsequent analysis were all fully anonymised, therefore explicit consent to do so was not required from the clients themselves.

\section{Study 1: Non-delivery of care}

We identified clients who had not had any inpatient hospital admissions during the 3-month study period. This was to identify an underlying study population for whom home care visit schedules would be relatively stable. Furthermore, home care visits cannot be delivered while a client is in hospital, and may also be altered after a hospital admission. Information on their weekday and weekend home care plans was collated and the total number of scheduled home care visits received was compared with the number of visits where a homecare worker attended, but did not deliver care. Visits where care was not delivered were recorded on the home care database as 'Service Refusal' or 'No Access'. These categorisations emanated from the social 
care provider records. 'Service Refusal' refers to a client not wishing to have the visit, and 'No Access' is where access to the client is not obtained. A random sample of $10 \%$ of such visits were selected and the explanatory text added by the homecare worker examined to ascertain the exact reason for non-delivery of care. Broad categories were defined to summarise these reasons. However, for all subsequent analyses 'Service Refusal' and 'No Access' were combined into one category of non-delivery of planned care.

We investigated the characteristics of those clients who did and did not receive all their planned care, and used this outcome measure as the dependent variable in a logistic regression analysis. Potential explanatory factors (covariates) included age, sex, ethnic group, home status and visit frequency. We also used a postcode measure of material deprivation, known as SIMD (Scottish Index of Multiple Deprivation) as a proxy measure for individual socio-economic status (Scottish Government, 2006). Odds ratios (with 95\% confidence intervals) were determined in univariate analyses for each covariate, and those that were statistically significant $(\mathrm{p}<0.05)$ were entered into the multivariate model. The adjusted odds ratios in the multivariate model represent the odds ratio for each covariate, simultaneously adjusted for all other covariates in the model.

\section{Study 2: Risk of emergency hospital admission}

A case-control study was conducted to assess whether non-delivery of care was associated with emergency risk of hospital admission. Cases were defined as clients who were admitted to hospital from their home as an inpatient emergency during the calendar month of December 2013. One control, matched for age and sex, was selected for each case. We used a consecutive sampling approach (the next eligible subject in an age/sex ordered list). These were clients who had no emergency hospital admission recorded in that month. Case or control status was used as the dependent variable in a logistic regression analysis. Whether or not there had been any instances of non-delivery of home care during the previous 3 month study period was assessed as an independent explanatory variable, as were home status, visit frequency and SIMD. Data on the underlying need for care, or co-morbidity, were not available. Odds ratios (with 95\% confidence intervals) were determined in univariate and multivariate analyses for each factor. 


\section{Findings}

\section{Study 1: Non-delivery of care}

From a total of 6,759 clients aged over 65 years, and receiving home care during the 3 -month study period, there were 4,815 who had no inpatient hospital admission during this period and constituted the study population. The majority (at least 58\%) of these clients were women, with $73 \%$ living in postcode areas categorised as being in the two lowest quintiles for measures of material deprivation. There was a fairly even distribution of visit frequency (ranging from 1 to 6 daily visits). The majority of clients were white British (at least 79\%) and around one half (at least $47 \%$ ) lived alone. The characteristics of the study population are presented in Table 1.

Over two-thirds (67\%) of the clients received all the home care that had been planned for them. However, among those for whom there were instances of non-delivery of care, the median number of undelivered visits was only two, with a range of one to 84 . The distribution was thus skewed, with only $3.6 \%$ of clients having more than one instance of undelivered care per week. This information is summarised in Table 1, stratified by socio-demographic characteristics. In a logistic regression analysis with any non-delivery of care as the dependent variable, being male and living alone (and home status unknown) were associated with increased likelihood of having at least one instance of non-delivery of care (as indicated by statistically significant unadjusted odds ratios of $>1$ in Table 1). There was also a statistically significant likelihood of non-delivery decreasing with increasing age. These associations persisted in the multivariate analysis after adjusting for visit frequency (which as might be expected was associated with increased likelihood of non-delivery).

From a 10\% sample of 960 instances of non-delivery of home care (among 427 clients) that were recorded as 'Service Refusal', no reason for this was given for $76(79 \%)$. Otherwise the client was in bed (8\%) or another reason was given (13\%). There were 4,170 instances of nondelivery of home care (among 1,411 clients) that were recorded as 'No Access'. Analysis of the explanatory text attached to 417 of the records indicated that the client was not present at home for 177 of the planned visits (out with others, pre-arranged appointment elsewhere, out on their own or whereabouts unknown). No care was required for 125 of the visits (the carer was either asked to return later, the service had been cancelled in advance, the service was not wanted, or someone else was providing care). The homecare worker had a mechanistic problem 
gaining access for 64 visits (eg missing key, doorbell not working etc), and the client was at home but did not answer the door for 49 visits.

\section{Study 2: Risk of emergency hospital admission}

There were 586 clients who were admitted to hospital from home as an emergency inpatient hospital admission in December 2013 and were defined as cases for a case-control study. Controls were identified for every case. In general, the characteristics of cases and controls were fairly similar (Table 2), although a higher proportion of cases came from more deprived postcode areas and there was also a trend for higher home case visit frequency in cases (during the previous 3-month period). There was also a higher proportion of cases with non-delivery of home visits during this time. There were 249 (42.5\%) cases who had any instances of nondelivery, ranging from one to 51 over a 3 month period. However, of these, $107(43.0 \%)$ had only one such non-delivered visit. The median number of such visits was two, with only eight cases having more than one such visit per week. In comparison, there were 194 (33.1\%) controls with any instances of non-delivery, ranging from one to 62, and of these $98(50.5 \%)$ had only one such visit. The median number was one, with only eleven controls had more than one per week. Patterns of non-delivery of home care therefore clearly differed between cases (those who had had an emergency hospital admission) and controls (those with no admission).

In the logistic regression analysis with emergency hospital admission as the dependent variable (i.e. whether a case or control), non-delivery of home care was a risk factor. The adjusted odds ratio (with $95 \%$ confidence intervals) was 1.53 (1.19-1.95). This association was evident even after adjusting for visit frequency. Having more than three visits daily was also associated with higher risk, with an adjusted odds ratio of 1.24 (0.90-1.70). The only other statistically significant association was observed for clients from the least deprived postcode areas who had half the risk of emergency hospital admission. 


\section{Discussion}

To our knowledge, is the first study that has explored patterns and reasons for non-delivery of planned home care among older people in a city in Scotland. Although we restricted the study to people who were not hospitalised during a 3-month study period (who may be a healthier and less vulnerable group of older people and therefore not fully representative of the home care population), it is reassuring that the majority of older people receive most of the home care that is planned for them. The median number of visits where care was not delivered was low. However, there are small numbers of clients with very high and persistent levels of nondelivery of care. We would therefore recommend that procedures for follow-up of non-delivery should be included by commissioners in a home care specification, and for providers to include in an operational manual, to guide daily practice. An important caveat of these results is that this study defined non-delivery of home care as visits where a home carer attended but did not deliver care. Instances of visits that were missed entirely due to non-attendance of the home care worker were not recorded, and their frequency remains unknown.

Instances of non-delivery were categorised as 'No Access' or 'Service Refusal'. However, in practice, there did not seem to be a clear cut distinction between the two and they were therefore combined in subsequent analyses. The reason for a high proportion of the 'Service Refusals' was not known and, in many cases, the textual explanations for non-delivery could have been more informative. We would therefore recommend a more consistent approach to recording non-delivery, with the reasons clearly explicated. This would facilitate planning future care to ensure that repeated non-delivery for avoidable reasons is eliminated where possible. There was a statistically significant association between decreased risk of non-delivery (and fewer undelivered visits) with increasing age, which is an encouraging result. However, there is evidence that men were more likely to have non-delivery than women, as were those living alone. Social isolation is a risk factor for adverse health outcomes and mortality (Steptoe et al, 2013) so it is particularly important that undelivered home visits are minimised in people living alone.

The case-control study showed that the odds of non-delivery of planned home care were higher among older clients who had an emergency inpatient admission (cases) than among controls. Given the complex array of risk factors that are associated with emergency hospital admission among older people (Wallace et al, 2014) and the relative infrequency of non-delivery of visits, 
we should be cautious in interpreting this association as a causal one. It could be due to uncontrolled confounding (but not by age and sex which were controlled for through matching). We know nothing about the clinical diagnoses or comorbidity of the home care clients; nor was there information available on the specific home care required. The underlying need for home care may be an important confounder. However, we have adjusted for frequency of home visits which could be a marker of vulnerability, and for living alone and deprivation, which have been shown to be associated with emergency hospital admission (Purdy and Huntley, 2013). The level of access to other health care staff (GPs and community nursing) might also confound the association.

It is important to have a means of identifying those who may be at high risk of adverse health and social consequences. Only a small number of risk prediction models for emergency hospital admission among older people have used non-medical variables and these are often quite limited and reliant upon self-report (Wallace et al, 2014); but the value of using social variables has been recognised (Purdy and Huntley, 2013). To know that non-delivery of care, for whatever reason, is associated with emergency hospital admission, could therefore be a useful indicator of vulnerable clients who may need increased surveillance.

The data sources used for this study were robust. The information on non-delivered visits was collected directly from the database of the social care provider, while the hospital admission records are part of a routinely collected national dataset with high standards of quality control (ISD Scotland, 2017). This study was carried out over a 3-month period in one City Council in Scotland. One company provides virtually all of the home care for this group. It is therefore difficult at this stage to know whether results would be similar for other home care providers.

Although this study has shown that it is feasible to record-link health and social care data for a small well-defined project, the ethical approval processes were complex and time-consuming, and considerable time needed to be spent on the development of a data sharing protocol between three stakeholders to ensure each had equal representation. The challenges surrounding larger-scale linkage projects are also substantial (Witham et al, 2015). In contrast, the actual linkage process was relatively straightforward, involving the probabilistic allocation of CHI numbers to social care data, then the deterministic linkage of these data to SMR1 data that were already CHI-indexed; an approach previously used in Scotland (Witham et al, 2015). The ethical and administrative burden for these types of studies would be reduced by having a 
common patient identifier for health and social care, but this has so far only been achieved in small scale projects or pilot sites (Maguire et al, 2018). In conclusion, our project has demonstrated important potential for innovative research into the quality of social care and its possible effects on health outcomes that was made possible through data linkage, but such studies could be facilitated in future with shared electronic records for health and social care. 


\section{References}

Bardsley M, Gheorghiou T, Chassin L, Lewis G, Steventon A, Dixon J. (2012) Overlap of hospital use and social care in older people in England. Journal Health Service Research Policy; 17 (3): 133-139

Care Quality Commission (CQC) (2013). Not just a number: Home care inspection programme - National overview. Newcastle: Care Quality Commission

Cattan M, Giuntoli G (2010). Care and support for older people and carers in Bradford: their perspectives, aspirations and experiences. York: Joseph Rowntree Foundation Henderson C (2006). Time and other inputs for high quality social care: Wanless social care review. London: King's Fund

House of Lords (2013). 'Ready for ageing?' Select Committee on Public Service and Demographic Change. Report of Session 2012-13. HL Paper 140. London: The Stationery Office Limited.

ISD Scotland (2017). National Data Catalogue. http://www.ndc.scot.nhs.uk/NationalDatasets/data.asp? ID $=1 \&$ SubID $=5$

Maguire D, Evans H, Honeyman M, Omojomolo D (2018). Digital change in health and social care. The Kings Fund.

National Institute for Clinical Excellence (2015). Home care: delivering personal care and practical support to older people living in their own homes. https://www.nice.org.uk/guidance/ng21

Office for National Statistics, 2015. National population projections for the UK.

Porter A, Morrison-Rees S. (2015) Can we reduce emergency hospital admissions through effective social care for older people? Emergency Medicine Journal; 32 (6): e16-e16

Purdy S, Huntley A (2013). Predicting and preventing avoidable hospital admissions: a review. J R Coll Physicians Edinb; 43:340-4

Scottish Government (2006). Using the Scottish Index of Multiple Deprivation 2006:

Guidance leaflet. http://www.gov.scot/Publications/2006/10/13142841/1

Scottish Government. (2011). Reshaping Care for Older People. A Programme for Change 2011-2021. http://www.gov.scot/Resource/0039/00398295.pdf

Steptoe A, Shankar A, Demakakos P, Wardle J. Social isolation, loneliness and all-cause mortality in men and women. PNAS 2013; 110:5797-5801. 
Wallace E, Stuart E, Vaughan N, Bennett K, Fahey T, Smith S (2014). Risk prediction models to predict emergency hospital admission in community-dwelling adults: A systematic review. Medical Care; 52:751-765.

Witham M, Frost H, McMurdo M, Donnan PT, McGilchrist M (2015). Construction of a linked health and social care database resource - lessons on process, content and culture. Inform Soc Health Care; 40:229-39 


\begin{tabular}{|c|c|c|c|c|c|}
\hline & \multicolumn{3}{|c|}{ Characteristics of study population } & \multicolumn{2}{|c|}{ Results of logistic regression } \\
\hline & Total & $\begin{array}{l}\text { Number }(\%) \text { of } \\
\text { people who did not } \\
\text { receive all their } \\
\text { home care visits }\end{array}$ & $\begin{array}{l}\text { Mean (median) } \\
\% \text { of home care } \\
\text { visits not } \\
\text { delivered } \\
\text { among those } \\
\text { who did not } \\
\text { receive all visits }\end{array}$ & $\begin{array}{l}\text { Odds ratio (with 95\% CI) } \\
\text { for likelihood of not } \\
\text { receiving all visits } \\
\text { (unadjusted) }\end{array}$ & $\begin{array}{l}\text { Odds ratio (with } \\
95 \% \mathrm{CI} \text { ) for likelihood } \\
\text { of not receiving all } \\
\text { visits (adjusted) }\end{array}$ \\
\hline \multicolumn{6}{|l|}{ Gender } \\
\hline Female & 2,789 & $1,029(36.9)$ & $2.8(1)$ & 1.00 & 1.00 \\
\hline Male & 1,213 & $511(42.1)$ & $3.9(2)$ & $1.25(1.09-1.43)$ & $1.18(1.02-1.36)$ \\
\hline Not known & 813 & $64(7.9)$ & $4.0(2)$ & - & - \\
\hline \multicolumn{6}{|l|}{ Age } \\
\hline $65-69$ yrs & 248 & $97(39.1)$ & $3.2(1)$ & 1.00 & 1.00 \\
\hline $70-74$ yrs & 490 & $181(36.9)$ & $3.6(2)$ & $0.92(0.67-1.25)$ & $0.89(0.64-1.24)$ \\
\hline $75-79$ yrs & 772 & $272(35.2)$ & $3.2(1)$ & $0.85(0.63-1.14)$ & $0.84(0.61-1.14)$ \\
\hline $80-84$ yrs & 1,153 & $392(34.0)$ & $3.6(2)$ & $0.80(0.60-1.06)$ & $0.78(0.58-1.05)$ \\
\hline $85-89$ yrs & 1,108 & $360(32.5)$ & $3.0(2)$ & $0.75(0.56-1.00)$ & $0.74(0.55-1.00)$ \\
\hline $90-94$ yrs & 753 & $224(29.7)$ & $2.9(1)$ & $0.66(0.49-0.89)$ & $0.61(0.45-0.84)$ \\
\hline$\geq 95 \mathrm{yrs}$ & 291 & $78(26.8)$ & $2.1(1)$ & $0.57(0.40-0.82)$ & $0.54(0.37-0.80)$ \\
\hline \multicolumn{6}{|l|}{ SIMD } \\
\hline $\begin{array}{l}1 \\
\text { deprived) }\end{array}$ & 2,652 & $891(33.6)$ & $3.1(2)$ & 1.00 & - \\
\hline 2 & 885 & $296(33.4)$ & $3.2(1)$ & $0.99(0.85-1.17)$ & - \\
\hline 3 & 403 & $126(31.3)$ & $2.4(1)$ & $0.90(0.72-1.13)$ & - \\
\hline 4 & 309 & $98(31.7)$ & $3.0(2)$ & $0.92(0.71-1.18)$ & - \\
\hline $\begin{array}{ll}5 & \text { (least } \\
\text { deprived) }\end{array}$ & 329 & $106(32.2)$ & $3.4(2)$ & $0.94(0.74-1.20)$ & - \\
\hline Not known & 237 & $87(36.7 \%)$ & $3.4(1)$ & $1.15(0.87-1.51)$ & - \\
\hline \multicolumn{6}{|l|}{ Ethnic group } \\
\hline White British & 3,798 & $1,260(33.2)$ & $3.2(2)$ & 1.00 & - \\
\hline $\begin{array}{l}\text { Ethnic minority } \\
\text { background }\end{array}$ & 47 & $17(36.2)$ & $2.2(2)$ & $1.14(0.63-2.08)$ & - \\
\hline Not known & 970 & $327(33.7)$ & $3.3(2)$ & $1.02(0.88-1.19)$ & - \\
\hline \multicolumn{6}{|l|}{ Home status } \\
\hline Other & 1,257 & $350(27.8)$ & $3.0(1)$ & 1.00 & 1.00 \\
\hline Living alone & 2,241 & $812(36.2)$ & $3.3(2)$ & $1.47(1.27-1.71)$ & $1.41(1.20-1.65)$ \\
\hline Not known & 1,317 & $442(33.6)$ & $3.3(2)$ & $1.31(1.11-1.55)$ & $1.40(1.17-1.67)$ \\
\hline \multicolumn{6}{|l|}{$\begin{array}{l}\text { Visit } \\
\text { frequency }\end{array}$} \\
\hline Up to 2 per day & 1,852 & $432(23.3)$ & $2.7(1)$ & 1.00 & 1.00 \\
\hline 2-4 per day & 1,969 & $816(41.4)$ & $3.5(2)$ & $2.33(2.02-2.68)$ & $2.30(1.99-2.66)$ \\
\hline 4 and above & 994 & $356(35.8)$ & $3.1(1)$ & $1.83(1.56-2.18)$ & $1.85(1.55-2.21)$ \\
\hline
\end{tabular}

Table 1: Characteristics of study population and results of logistic regression analysis: the dependent variable is whether all planned visits were delivered (Study 1) 


\begin{tabular}{|c|c|c|c|c|}
\hline & Cases & Controls & $\begin{array}{l}\text { Odds ratio (with 95\%CI) } \\
\text { (unadjusted) }\end{array}$ & $\begin{array}{ll}\text { Odds } & \text { ratio (with } \\
95 \% \mathrm{CI} \text { ) } & \text { (adjusted) } \\
\end{array}$ \\
\hline \multicolumn{5}{|l|}{ Gender } \\
\hline Female & $308(52.6 \%)$ & $311(53.1 \%)$ & - & - \\
\hline Male & $155(26.5 \%)$ & $153(26.1 \%)$ & - & - \\
\hline Not known & $123(21.0 \%)$ & $122(20.8 \%)$ & - & - \\
\hline \multicolumn{5}{|l|}{ Age } \\
\hline $65-74$ yrs & $89(15.2 \%)$ & $89(15.2 \%)$ & - & - \\
\hline $75-84$ yrs & $242(41.3 \%)$ & $242(41.3 \%)$ & - & - \\
\hline $85-94$ yrs & $215(36.7 \%)$ & $215(36.7 \%)$ & - & - \\
\hline$\geq 95 \mathrm{yrs}$ & $40(6.8 \%)$ & $40(6.8 \%)$ & - & - \\
\hline \multicolumn{5}{|l|}{ SIMD } \\
\hline $\begin{array}{l}1 \text { (most } \\
\text { deprived) }\end{array}$ & $359(61.3 \%)$ & $339(57.8 \%)$ & 1.00 & 1.00 \\
\hline 2 & $110(18.8 \%)$ & $102(17.4 \%)$ & $1.02(0.75-1.39)$ & $1.04(0.76-1.41)$ \\
\hline 3 & $43(7.3 \%)$ & $41(7.0 \%)$ & $0.99(0.63-1.56)$ & $1.02(0.64-1.61)$ \\
\hline 4 & $41(7.0 \%)$ & $40(6.8 \%)$ & $0.97(0.61-1.53)$ & $0.99(0.62-1.58)$ \\
\hline $\begin{array}{l}5 \text { (least } \\
\text { deprived) }\end{array}$ & $21(3.6 \%)$ & $36(6.1 \%)$ & $0.55(0.32-0.96)$ & $0.55(0.31-0.96)$ \\
\hline Not known & $12(2.0 \%)$ & $28(4.8 \%)$ & $0.41(0.20-0.81)$ & $0.38(0.19-0.76)$ \\
\hline \multicolumn{5}{|l|}{ Home status } \\
\hline Other & $170(29.0 \%)$ & $168(28.7 \%)$ & 1.00 & - \\
\hline Living alone & $265(45.2 \%)$ & $262(44.7 \%)$ & $1.00(0.76-1.31)$ & - \\
\hline Not known & $151(25.8 \%)$ & $156(26.6 \%)$ & $0.96(0.70-1.30)$ & - \\
\hline \multicolumn{5}{|l|}{$\begin{array}{l}\text { Visit } \\
\text { frequency }\end{array}$} \\
\hline Up to 1 per day & $143(24.9 \%)$ & $162(27.6 \%)$ & 1.00 & 1.00 \\
\hline Up to 2 per day & $141(24.1 \%)$ & $150(25.6 \%)$ & $1.07(0.77-1.47)$ & $0.98(0.70-1.36)$ \\
\hline Up to 3 per day & $111(18.9 \%)$ & $118(20.1 \%)$ & $1.07(0.76-1.50)$ & $0.94(0.66-1.34)$ \\
\hline 3 and above & $191(32.6 \%)$ & $156(26.6 \%)$ & $1.39(1.02-1.89)$ & $1.24(0.90-1.70)$ \\
\hline \multicolumn{5}{|l|}{$\begin{array}{l}\text { Any missed } \\
\text { visits }\end{array}$} \\
\hline Range (median) & $1-51(2)$ & $1-62(1)$ & & \\
\hline No & $337(57.6 \%)$ & $392(66.9 \%)$ & 1.00 & 1.00 \\
\hline Yes & $249(42.5 \%)$ & $194(33.1 \%)$ & $1.49(1.18-1.89)$ & $1.53(1.19-1.95)$ \\
\hline
\end{tabular}

Table 2: Characteristics of cases and controls and results of logistic regression analysis (Study 2) 
Fig 1: Showing study period and study population for Study 1 and Study 2

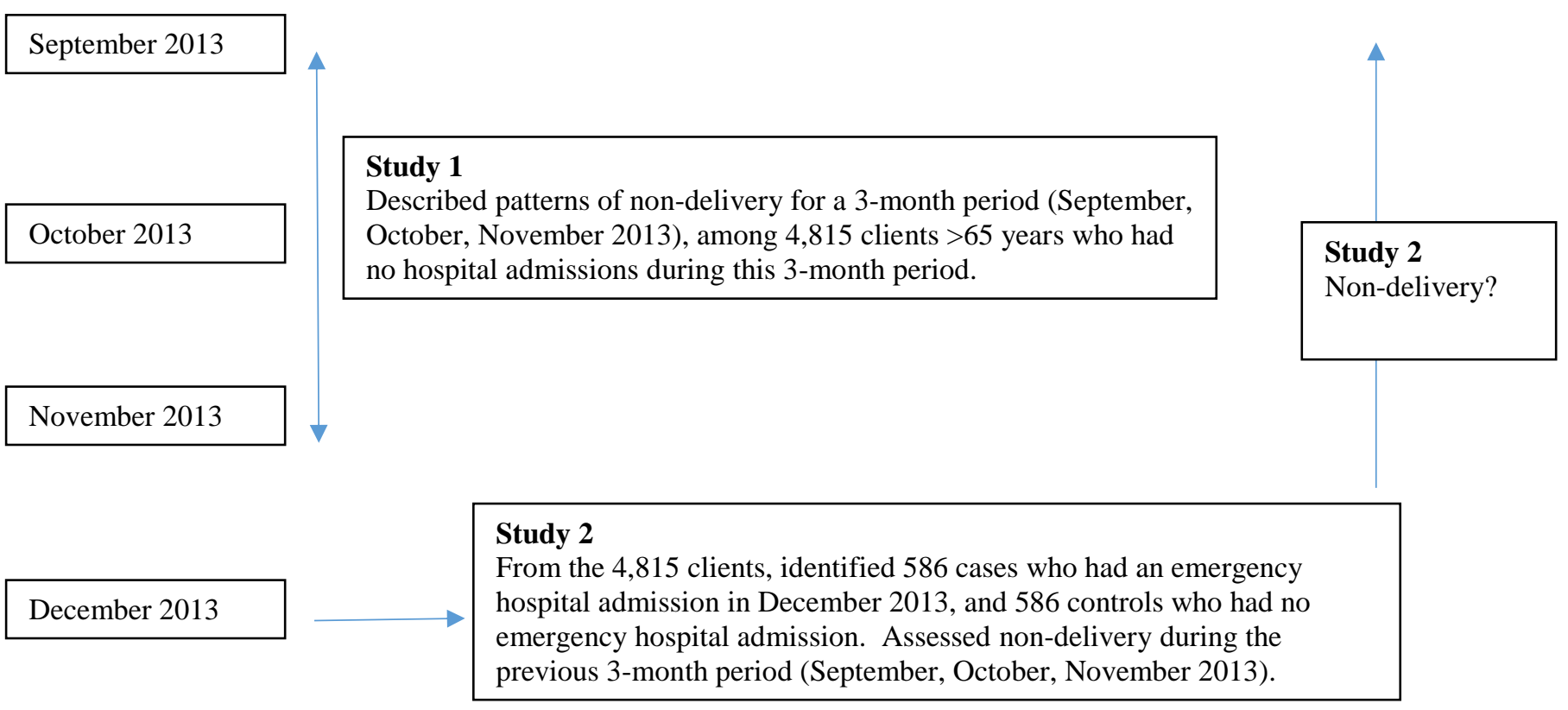




\section{Acknowledgements}

\section{Declaration of Competing Interests}

The authors have no Conflicts of Interest in relation to the submitted work.

\section{Authors' Contributions}

All authors had full access to all of the data in the study and can take responsibility for the integrity of the data and the accuracy of the data analysis. KM managed the project on a day to day basis, and conducted preliminary analyses. JE conducted further analysis and co-wrote the paper with KM. All authors commented on drafts of the paper and approved the final version.

\section{Role of Study Sponsor}

The University of Stirling was the study sponsor. The researchers were independent of the study sponsor. 